\title{
Biopiracy of natural products and good bioprospecting practice
}

\section{Thomas Efferth ${ }^{\mathrm{a}, *}$, Mita Banerjee ${ }^{\mathrm{b}}$, Norbert W. Paul ${ }^{\mathrm{c}}$, Sara Abdelfatah ${ }^{\mathrm{a}}$, Joachim Arend ${ }^{\mathrm{a}}$, Gihan Elhassan ${ }^{\text {a,d }}$, Sami Hamdoun ${ }^{a}$, Rebecca Hamm ${ }^{\text {a }}$, Chunlan Hong ${ }^{a}$, Onat Kadioglu ${ }^{a}$,} Janine Naßa, Dominic Ochwangi ${ }^{a, e}$, Edna Ooko ${ }^{a}$, Nadire Ozenver ${ }^{a}$, Mohamed E.M. Saeed ${ }^{a}$, Mathias Schneider ${ }^{a}$, Ean-Jeong Seo ${ }^{a}$, Ching-Fen $\mathrm{Wu}^{\mathrm{a}}$, Ge Yan ${ }^{\mathrm{a}}$, Maen Zeino ${ }^{\mathrm{a}}$, Qiaoli Zhao ${ }^{\mathrm{a}}$, Mohammad S. Abu-Darwish ${ }^{\mathrm{f}}$, Kai Andersch ${ }^{\mathrm{g}}$, Gladys Alexie ${ }^{\mathrm{h}}$, Dawn Bessarab ${ }^{\mathrm{i}}$, Dipita Bhakta-Guha ${ }^{j}$, Vanderlan Bolzani ${ }^{k}$, Else Dapat ${ }^{1}$, Fedor V. Donenko ${ }^{\mathrm{m}}$, Monika Efferth ${ }^{\mathrm{a}}$, Henry J. Greten ${ }^{\mathrm{n}}$, Leslie Gunatilaka ${ }^{\circ}$, Ahmed A. Hussein ${ }^{\mathrm{p}}$, Asuman Karadeniz ${ }^{\mathrm{q}}$, Hassan E. Khalid ${ }^{\mathrm{r}}$, Victor Kuete ${ }^{\mathrm{s}}$, Ik-Soo Lee ${ }^{\mathrm{t}}$, Liang Liu ${ }^{\mathrm{u}}$, Jacob Midiwov", Rodrigo Moraw, Hiroshi Nakagawa ${ }^{\mathrm{x}}$, Olipa Ngassapa ${ }^{\mathrm{y}}$, Chanai Noysang ${ }^{\mathrm{z}}$, Leonida K. Omosav, Fred Hwiemtun Roland ${ }^{\mathrm{aa}}$, Abdelaaty A. Shahat ${ }^{\mathrm{ab}, \mathrm{ac}, 1}$, Antoine Saab ${ }^{\text {ad }}$, Elfatih M. Saeed ${ }^{\text {ae }}$, Letian Shan ${ }^{\text {af }}$, Salam J.J. Titinchi ${ }^{p}$

a Department of Pharmaceutical Biology, Institute of Pharmacy and Biochemistry, Johannes Gutenberg University, Staudinger Weg 5, 55128 Mainz, Germany ${ }^{\mathrm{b}}$ Department of English and Linguistics, Johannes Gutenberg University, Mainz, Germany

${ }^{c}$ Institute for History, Theory and Ethics of Medicine, Johannes Gutenberg University Medical Center, Mainz, Germany

${ }^{\mathrm{d}}$ Department of Botany, Faculty of Science, University of Khartoum, Khartoum, Sudan

e Department of Veterinary Anatomy and Physiology, University of Nairobi, Nairobi, Kenya

f Shoubak University College, Al-Balqa Applied University, Jordan

${ }^{\mathrm{g}}$ Wilderness International, Dresden (Germany) and Stony Plain, Alberta, Canada

h Fort McPherson, Northwest Territories, Canada

i Center for Health Innovation Research Institute, Faculty of Health Sciences, Curtin University, Perth, Western Australia

iSchool of Chemical and Biotechnology, SASTRA University, Thanjavur 613401, T.N., India

${ }^{\mathrm{k}}$ Department of Organic Chemistry, Institute of Chemistry, São Paulo State University, Araraquara, Brazil

${ }^{1}$ Department of Biology, University of the Philippines, Manila City, and Institute of Biology, University of the Philippines, Dilman, Quezon City, Philippines

${ }^{\mathrm{m}}$ N.N. Blokhin Russian Cancer Research Center, Moscow, Russia

${ }^{n}$ Biomedical Sciences Institute Abel Salazar, University of Porto, Porto, Portugal and Heidelberg School of Chinese Medicine, Heidelberg, Germany

${ }^{\circ}$ Southwest Center for Natural Products Research and Commercialization, School of Natural Resources and the Environment, Tucson, Arizona, United States $\mathrm{p}$ Chemistry Department, University of Western Cape, Belleville, South Africa

${ }^{\mathrm{q}}$ Mehmet Akif Ersoy University, Biology Department, Burdur, Turkey

${ }^{r}$ Department of Pharmacognosy, University of Khartoum, Khartoum, Sudan

s Department of Biochemistry, Faculty of Science, University of Dschang, Dschang Cameroon

${ }^{\mathrm{t}}$ College of Pharmacy, Chonnam National University, Gwangju, Republic of Korea

"Macao University of Science and Technology, Macao, China

${ }^{v}$ Department of Chemistry, University of Nairobi, Nairobi, Kenya

${ }^{\mathrm{w}}$ Faculty of Microbiology, Rodrigo Facio University, San José, Costa Rica

x Department of Applied Biological Chemistry, College of Bioscience and Biotechnology, Chubu University, Kasugai, and Department of Biomolecular

Engineering, Graduate School of Bioscience and Biotechnology, Tokyo Institute of Technology, Yokohama, Japan

y Muhimbili University of Health and Allied Sciences, Dar es Salaam, Tanzania

${ }^{z}$ Department of Pharmacognosy, Faculty of Pharmacy, Mahidol University, Bangkok, Thailand and Traditional Medicine College, Rajamangala University of Technology Thayaburi, Phathumthani, Thailand

${ }^{a}$ Duncan, Vancouver Island, Canada

ab Pharmacognosy Department, College of Pharmacy, King Saud University, Riyadh, Saudi Arabia

ac Phytochemistry Department, National Research Center, Cairo, Egypt

ad Faculty of Sciences II, Lebanese University, Chemistry Department, Beirut, Lebanon

ae Federal Government of Sudan, Khartoum, Sudan

af Zhejiang Chinese Medical University, Hangzhou, China

\footnotetext{
* Corresponding author. Tel.: +49 6131 3925751; fax: +49 61313923752.

E-mail address: efferth@uni-mainz.de (T. Efferth).

Home address: Phytochemistry Department, National Research Center, Dokki, Cairo, Egypt.
} 


\section{A R T I C L E I N F O}

\section{Article history:}

Received 22 October 2015

Revised 30 November 2015

Accepted 4 December 2015

\section{Keywords:}

Bioethics

Bioprospecting

Commercialization

Indigenous knowledge

Intellectual property

Patent

\section{A B S T R A C T}

Background: Biopiracy mainly focuses on the use of biological resources and/or knowledge of indigenous tribes or communities without allowing them to share the revenues generated out of economic exploitation or other non-monetary incentives associated with the resource/knowledge.

Methods: Based on collaborations of scientists from five continents, we have created a communication platform to discuss not only scientific topics, but also more general issues with social relevance. This platform was termed 'PhytCancer -Phytotherapy to Fight Cancer' (www.phyt-cancer.uni-mainz.de). As a starting point, we have chosen the topic "biopiracy", since we feel this is of pragmatic significance for scientists working with medicinal plants.

Results: It was argued that the patenting of herbs or natural products by pharmaceutical corporations disregarded the ownership of the knowledge possessed by the indigenous communities on how these substances worked. Despite numerous court decisions in U.S.A. and Europe, several international treaties, (e.g. from United Nations, World Health Organization, World Trade Organization, the African Unity and others), sharing of a rational set of benefits amongst producers (mainly pharmaceutical companies) and indigenous communities is yet a distant reality. In this paper, we present an overview of the legal frameworks, discuss some exemplary cases of biopiracy and bioprospecting as excellent forms of utilization of natural resources.

Conclusions: We suggest certain perspectives, by which we as scientists, may contribute towards prevention of biopiracy and also to foster the fair utilization of natural resources. We discuss ways, in which the interests of indigenous people especially from developing countries can be secured.

(C) 2015 Elsevier GmbH. All rights reserved.

\section{Preface}

Based on scientific collaborations of the Department of Pharmaceutical Biology (Johannes Gutenberg University, Mainz, Germany) with scientists from across five continents working on ethnopharmacological projects during the past decade, an informal communication network has been formed, named 'PhytCancer - Phytotherapy to Fight Cancer' (www.phyt-cancer.uni-mainz.de). The aim is to provide an independent, non-commercial, and academic platform for the exchange of scientific knowledge and to promote rational development of highly effective, yet affordable phytotherapeutic drugs contrary to the high-priced cancer drugs or conventional medicine. Another goal of PhytCancer is to discuss societal problems related to ethnomedicine and ethnopharmacology. As a starting point of this new communication platform, we herein discuss problems associated with the unethical use and commercialization of bioresources and traditional knowledge of indigenous communities. In this respect, PhytCancer projects itself as an interdisciplinary forum at the interface between life science and the humanities.

\section{Introduction}

The term biopiracy was coined in the $1990 \mathrm{~s}$ by environmentalists and non-governmental organizations and has been frequently used in public discussion platforms in and beyond the life science community. However, the correctness of its use has been criticized by scholars of jurisprudence (Chen 2006; Ho 2006). Independent from controversial and partly emotional discussions among different social groups, biopiracy mainly focuses on the use of biological resources and/or knowledge of indigenous tribes or communities without sharing the revenues earned out of economic and nonmonetary exploitation of such resources (Hamilton 2006; Brody 2010). Another related issue is the ownership of knowledge (Shiva 1999). It was argued that the patenting of herbs or natural products by pharmaceutical corporations disregarded the ownership of the indigenous communities' knowledge on how these substances worked. Prior to very recent court decisions, neither native communities could provide evidence of their ownership of the knowledge, nor the evidence (in case provided) was recognized by the courts. Because of this legal situation, the patenting of indigenous knowledge by pharmaceutical corporations was seen by critics as a new form of colonialism (Shiva 1999). Thus, any discourse on biopiracy is meaningful only if it caters to the protection of intellectual rights of people associated with the knowledge of the resources in question. This broader perspective would definitely facilitate evidence-driven rather than interest-driven dialogues. For a first overview, we performed a PubMed search on the published biomedical literature of more than half a century with selected search terms. PubMed is a free archive of biomedical and life sciences journal literature at the U.S. National Institutes of Health's National Library of Medicine (NIH/NLM). (http://www.ncbi.nlm.nih. gov/pubmed). PubMed comprises more than 24 million citations for biomedical literature from different sources, which may include links to full-text content from PubMed Central and publisher web sites. As shown in Fig. 1A, there is a steadily increasing number of publications containing the key word "patent". This number exceeded 1500 publications per year since 2011. To a lesser extent, this trend is also visible for publications dealing with the search term "intellectual property". "Bioethics" also exhibited an upward trend since 1960. However, the number of papers published annually on this topic declined after 2005. In general, it can be summed up that topics related to patents, intellectual rights, or bioethics have been forerunners of interest among scientists working in biomedicine irrespective of their sub-disciplines.

This presents a sharp contrast to what can be observed, if we focus on search terms specifically related to problems discussed here. Although the number of publications containing the search terms 'bioprospecting' or 'indigenous knowledge' have pleasantly increased during the past decade, the total number of annually published papers is about two orders of magnitude lesser (Fig. 1B). This striking result indicates that problems related to the utilization of indigenous knowledge do not occupy a central interest among the general scientific community. This becomes clearer while searching for PubMed-listed papers on 'biopiracy'. The number of papers remains below 10 without any significant upward trend over the years. These facts and figures illustrate how imperative it is to make the scientific community aware of this issue. It is a well-known fact from cultural studies that awareness is the first step towards providing effective and substantial protection of indigenous knowledge. This leaves us with the pragmatic question 'What has to be regarded as biopiracy? 


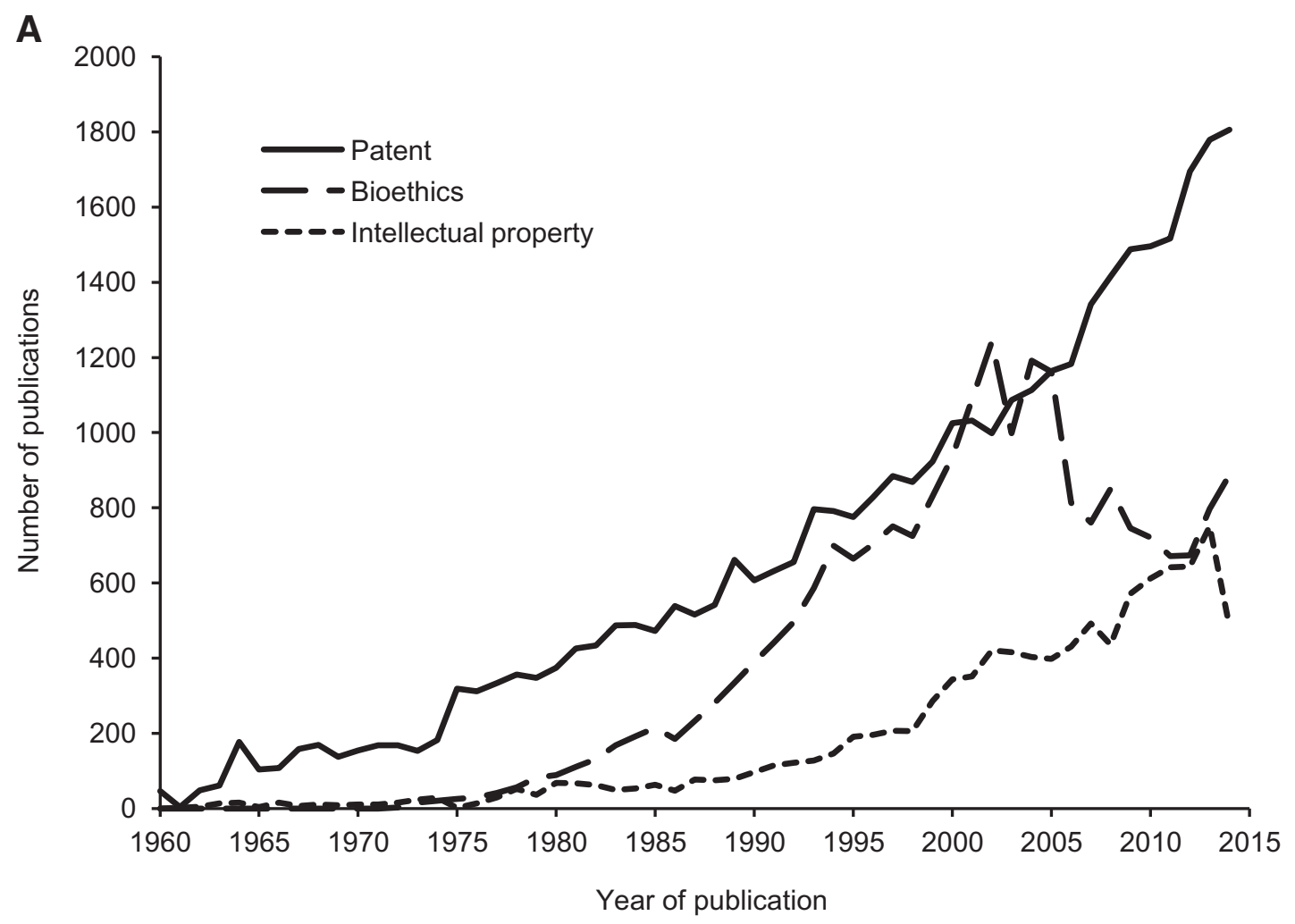

B

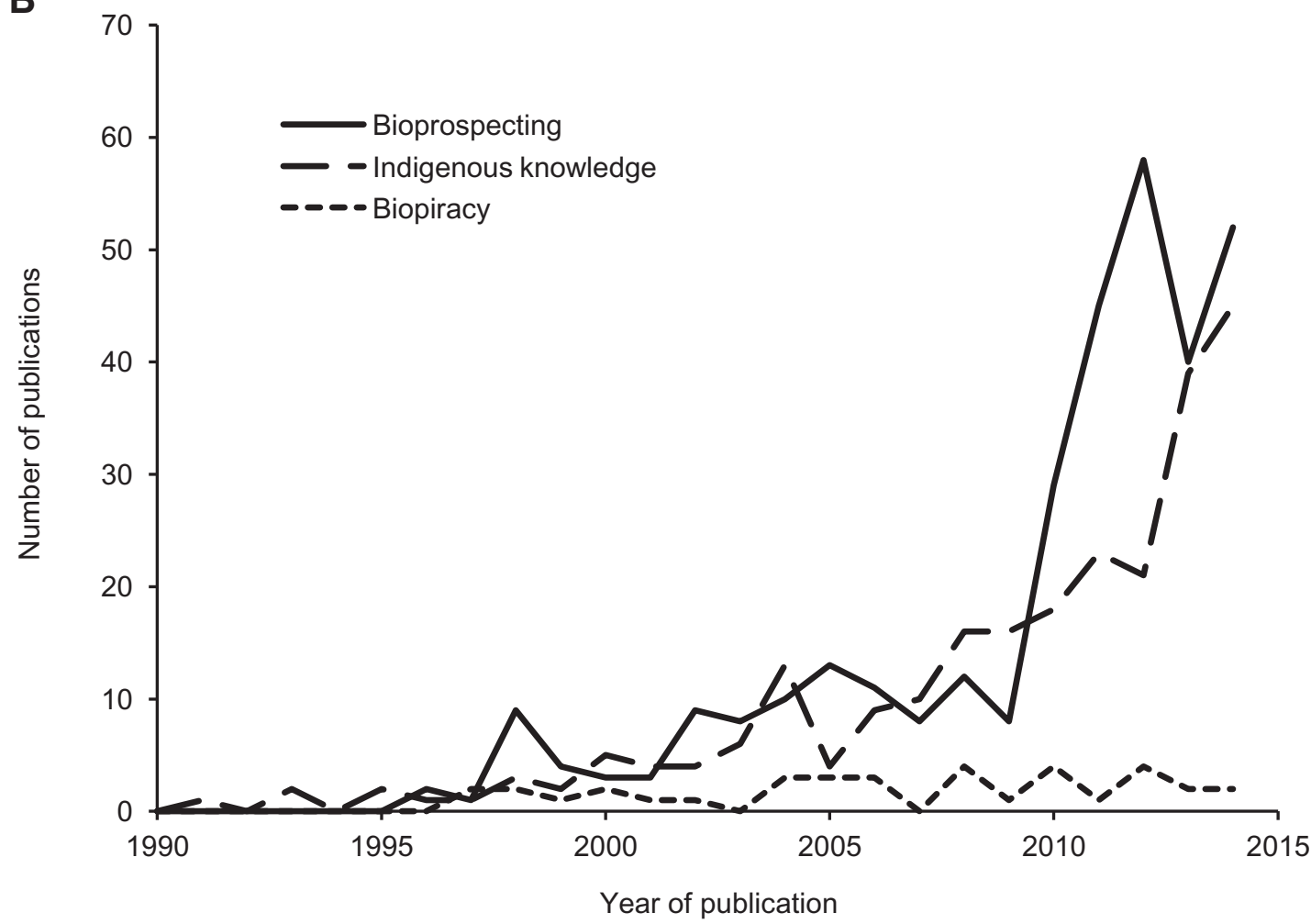

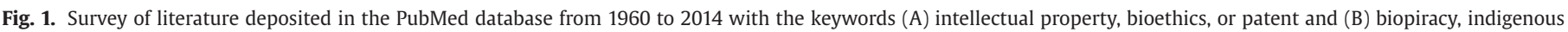
knowledge, or bioprospecting.

There is a wide range of possibilities ranging from

(1) Patent- or non-patent-based forms of biopiracy, i.e. patenting of inventions based on traditional indigenous knowledge or trademark protection of foreign intellectual property of traditional knowledge.
(2) Patent- or non-patent-based use of traditional knowledge can occur with or without knowledge of the affected indigenous communities. The use of traditional knowledge or biomaterials can be understood as burglary and is to be handled (legally or at least morally) as a criminal act. 
Prior to 1980, the courts in USA interpreted the patent statute as a decree to prohibit the patenting of living matter altogether. Living organisms per se were claimed to be products of nature and were, therefore, ear marked as non-patentable. It said that such naturally occurring materials are "manifestations of ... nature, free to all men and served exclusively to none." (U.S. Supreme Court 1948). However, we now know that natural products could be claimed in any new form or composition or derivative. Nonnaturally occurring purities, concentrations or combinations of these substances are conditionally patentable.

In the 1980s, right to patent living material was granted. In the landmark case of Diamond v. Chakrabarty (U.S. Supreme Court 1980), the American Supreme Court allowed a patent on a bacterium transfected with DNA that allegedly enhanced its ability to degrade hydrocarbons in order to cleanse oil spills in oceans. The Court held that living man-made microorganisms represent a patentable subject matter as 'manufacture' or 'composition of matter'. As to DNA patentability, the U.S. Supreme Court upheld that DNA sequences are non-obvious and therefore also patentable (U.S. Patent and Trademark Office 1991, 1993).

While in Europe, according to the European Patent Convention of 1973 (EPC), patents would not be granted in respect of (a) inventions, which would be contrary to the public order or morality, and (b) plant or animal varieties or essential biological processes responsible for the production of plants or animals. However, patents could be obtained for microbiological processes or the products derived from them ( $\$ 53$, EPC 1973). The British Patents Act of 1977 (S.I (3, b) follows the EPC, to the effect that patents cannot be granted for any variety of animal or plant or any essential biological process responsible for the production of animals or plants. The said Act, however, protects microbiological processes or those involving microscopic life forms (Intellectual Property Office 1977).

The ability to create recombinant living organisms with advanced DNA technology designed to "improve" characteristics resulted in the production of the "onco-mouse" (European Patent Office 1991). This genetically modified animal represents itself as a template of cancer and is extremely helpful in carrying out basic cancer research. This mouse was however patentable despite the prohibition of patenting animal varieties. Subsequently, The Board of Appeal in the European Patent Office stated that patenting such animals is not prohibited (MacQueen 1994).

The non-patentability of natural products also includes chemical structures. Simple isolation of a chemical substance from nature is not patentable, since it is a mere discovery. A synthetically produced chemical with the same structure as an existent natural compound is not patentable either. However, if the product is of significant purity and was previously unidentified in its purified or isolated form, it may be patentable as a substance, because now it represents not just a purification process rather a new substance altogether (Kadidal 1993).

In the same context, the claim for crystalline vitamin B12 (which does not exist in nature) was undermined due to presence of even slightest impurities. To qualify for a purification patent, the level of purity should be high enough to allow the product to be distinguished, and to be made medicinally useful (Kadidal 1993). In a previous case, adrenalin was transformed by the patentee's purification process into a useful drug.

\section{Examples of biopiracy and bioprospecting}

While biopiracy certainly represents an extreme situation (although it might occur frequently), the use of natural resources makes much sense in many cases and does not necessarily include criminal, illegal or suspicious acts. A more general term is 'bioprospecting', which describes the identification and commercializa- tion of bioproducts. Hence, bioprospecting includes both biopiracy practices as well as the proper use of natural resources respecting the identities, interests and rights of indigenous communities (Puri et al. 2010).

To demonstrate the dimension of biopiracy and bioprospecting, we mention herein a few selected examples from across five continents, which would illustrate the width and difficulty of this field and that clear-cut "black-or-white" decisions are not always easy to conclude. The presence of several gray shades pose as blurred lines demanding for a more thorough debate on issues of biopiracy in the future. This problem is illustrated by the fact that the growth of many medicinal plants is not restricted to limited and defined areas. They may grow more or less ubiquitously in large areas panning the globe. The medicinal effects of such plants (e.g. their antiinflammatory, wound-healing or anti-diarrhea activity) may have been independently recognized by several indigenous communities in different countries. Hence, it may be difficult to assign indigenous knowledge to a geographically defined area or to a certain indigenous community within this area.

Asia: Curcuma (Curcuma longa L.) is not only a delicious spice in Asian cuisines, it has also traditionally been used for ages to treat wounds and rashes in India (Gupta et al. 2013). A U.S.-American patent of two Indian scientists on curcuma as a drug to treat wounds has been retracted. The Indian Council for Scientific and Industrial Research (CSIR) successfully sued the U.S. Patent Office, because these medical effects of curcuma have been mentioned in an ancient Sanskrit text, which was published in 1953 in the Journal of the Indian Medical Association (British Parliament 1999). This is an unambiguous example of biopiracy, which also demonstrates the importance of written documentation for preventing the same. The decision to revoke the patent by the U.S. Patent Office marks a turnaround in the legal framework in that it respects indigenous knowledge handed down in ancient texts. These texts, such as Hindu epics, which link medical knowledge to cultural and religious tradition, are themselves recognized as evidence of the ownership of medical knowledge by a given community. The Agreement of the Trade Related Aspects of Intellectual Property Rights (TRIPS) gives an overview in Article 27.3(b), specifically discussing the patentability or non-patentability of plant and animal inventions, and the protection of plant varieties (World Trade Organization 2015a).

Australia: There is a still ongoing controversy on the Kakadu plum (Terminalia fernandiana Excell). The fruit contains unusually high contents of vitamin $C$ and has been used as bush food by the Australian Aboriginal people during long hunting trips (Robinson 2010). A U.S.-American cosmetics company is seeking for a patent. As the U.S.A. did not sign international conventions on this topic (see below), the chances are bleak that the Aborigines will participate on the revenues generated out of the commercialization of products made from Kakadu plum. Opponents argue that the patent does not report on innovative invention, due to the long history of traditional use. It remains to be seen whether Aboriginal communities will be able to provide evidence proving their knowledge of the medicinal use of the Kakadu plum (Timmermans 2003). In the case of Aboriginal communities, this is especially complicated, because indigenous communities in Australia as well as New Zealand have been traditionally oral cultures where knowledge has been handed down from generation to generation. Unlike in India, there may thus be fewer written documents recording Aboriginal medical knowledge of natural plants. The 2001 Doha Declaration (Paragraph 19) has further broadened this discussion (World Trade Organization 2015b). It states that the TRIPS Council should also look at the relationship between the TRIPS Agreement and the UN Convention on Biological Diversity concerning the protection of traditional knowledge and folklore. It adds that the TRIPS Council's work on these topics should be guided by the objectives 
and principles of TRIPS Agreement and must take development issues fully into account.

America: Wild mandrake (Mayapple, Indian apple, Podophyllum peltatum L.) has been used by the North-American First Nations to treat warts (Ray 2009). Systematic investigations revealed that the active chemical component of the plant is podophyllotoxin. Since decades, chemical derivatives of podophyllotoxin, etoposide and teniposide, constitute standard drugs in clinical oncology. This example points to another problem: some diseases were unknown in traditional medicines. In the case of cancer for instance, transliterations have been used. Terms such as swellings, ulcers, inflammation etc. have been used or proliferative symptoms such as skin warts. These have been treated e.g. by P. peltatum or other cytotoxic plants. It is a matter of discussion whether or not the anti-cancer activity of $P$. peltatum belongs to the wider circle of traditional knowledge. As a respite, according to the World Intellectual Property Organization (WIPO), it is possible to patent a well-known traditionally used chemical for a new bioactivity, which is not known earlier and thereby protecting the resource as well as associated indigenous knowledge (WIPO 2015).

Africa: Vincristine and vinblastine are putative and clinically established anticancer drugs that are in use since several decades. They are derived from the Madagascar periwinkle (Catharanthus roseus L., formerly Vinca rosea L.). This plant has been used by the natives not to treat cancer, but diabetes (Noble 1990). The question arises here, whether or not the identification of the two Vinca alkaloids as anticancer drugs was rather the result of experimental investigations in the laboratory than a consequence of the indigenous knowledge. The WIPO statement applies here too, because the anticancer activity in this case, is a new bioactivity that was not known earlier, and therefore is patentable.

Europe: European phytotherapy has a long and well-known tradition. Striking examples of biopiracy are rather rare, probably owing to the fact that the use of European medicinal plants is commonly accepted as general knowledge. While biopiracy has been intensively discussed for indigenous tribes from countries worldwide, it is not well recognized in this context that indigenous tribes also exist in Europe (e.g. the Basques in Spain, the Sami in Finland, the Sorbes in Germany and so on). Although there are some indigenous communities in Europe, potential issues regarding intellectual property rights on their traditional knowledge has been widely neglected so far. Alternatively, their cultural heritage does not seem to contain traditional medicinal practices, which are strikingly different from the ones of main European populations. Hence, there is not much concern about biopiracy in the context of European plants. Of course, numerous phytotherapeutic products are commercialized and sold in the market. In case there are patents on these products, they focus on technical production processes rather than on the medicinal effects of the plants themselves. Furthermore, products without patent protection can also be successfully marketed emphasizing on the aspect that patenting is not a sine qua non condition.

Definitely, these are only very few examples out of a long list that could be arbitrarily extended. On the other hand, the current practice is not morally questionable or even illegal in all cases. Indeed, there are also discussions on positive examples for the implementation of transparent and effective access and benefit sharing practices that encourage sound deal-making in bioprospecting (Krattiger 2009).

At least at this point, it becomes quite clear that bioprospecting and biopiracy are topics, which are at the center of research on medicinal plants. The current debate on biopiracy thus hinges on two inter-related issues. Firstly, it centers on the question, whether indigenous communities can provide written evidence of their ownership of knowledge. Secondly, there is the question of proving the efficacy of natural plants through methods of mod- ern pharmacological and molecular biological sciences. Some critics have argued that this may in itself be a disregard of indigenous knowledge, since this knowledge is recognized only, if it is validated by science. Yet, it can conversely be argued that this form of validation restores to indigenous communities recognition of ancient knowledge systems, which had been hitherto disregarded by science. What is crucial in terms of such validation, however, is that some critics fear that the revealing of the potency of natural products and hence the translation of indigenous knowledge into scientific terms is the first step towards the appropriation of such knowledge by pharmaceutical corporations.

\section{Who takes care?}

The traditional knowledge of indigenous communities is one of the most relevant topics for scientists working in

- ethnopharmacology, if it comes to the use of medicinal plants to treat diseases and ailments

- nutrition, if it comes to the use of plants traditionally used as foods

- ethnobotany, if it is about the plants used for housing, cloth production, ritualistic uses etc.

- organic chemistry/natural product chemistry/phytochemistry, if chemical molecules are isolated from plants, which are traditionally used (bioactivity-guided isolation)

Therefore, it is necessary that we, as academicians not working in pharmaceutical or other companies, discuss and realize whether or not we all intentionally or unintentionally violate rights inherently belonging to indigenous communities. This question arises, because we are performing research with medicinal and aromatic plants that are frequently based on traditional cultural systems.

Of course, this issue is not new and countless discussions on this topic have led to some practical attempts to restrict biopiracy practices (Mackey and Liang 2012; Abramova and Greer 2013). The present patent system may be considered inappropriate for the protection of plant varieties, since plant material is not capable of meeting the requirements of novelty and invention. It is not in the public interest to permit an extensive monopoly over plant varieties, which are of common importance. For this reason, a sui generis legislation for the protection of plant varieties seems to be appropriate. A sui generis contract is not regulated by existing laws. Such contracts are generally permitted and legally valid, as long as they do not infringe existing laws. The TRIPS agreement substantially regulated the domestic law of signatory countries. Plant varieties should at least be protected by an effective sui generis system. Article 27.1 states that patents shall be "available for any inventions, whether products or processes, in all fields of technology, provided that they are new, include an invention and are capable of industrial application." (World Trade Organization 2015a). However, there are two exceptions:

(1) Inventions may be excluded from patentability, where the prevention of its commercial exploitation is "necessary to protect public order or morality, including human, plant life or animal health or avoid serious prejudice to the environment" (§27)

(2) Plants and animals other than microorganisms may be excluded from patentability. This also applies to essential biological processes, which are used for the production of plants or animals (other than non-biological and microbiological processes) (§27). Thus, protection of plant varieties is only possible as a sui generis system as stated by the Union international pour la protection des obtentions végétales (UPOV 1991). 
Unfortunately (or should we say: Expectedly?), such political approaches have achieved rather modest success. The situation is similar to those "slow burning" problems, which are to a large extent characterized by their latency and which have to be realized at a global scale, e.g. the reduction of $\mathrm{CO}_{2}$ emission to stop global warming, the Great Pacific and Atlantic Garbage Patches with their emissions of artificial plastic softeners in the food chain etc.

Long before the term biopiracy was created, the World Health Organization (WHO) and the United Nations Educational, Scientific, and Cultural Organization (UNESCO) promoted international attention on how necessary it was to protect indigenous knowledge in the context of intellectual property rights (Tedlock 2006; UNEP 2015).

The United Nations General Assembly launched the Declaration on the Rights of Indigenous People (UN DRIP) (UN General Assembly 2007). This document described the right of indigenous tribes to control their own traditional knowledge. By giving them national status, these rights could be enforced by treaty or domestic legislation, although UN DRIP is not legally binding. The launching of UN DRIP provided indigenous communities world-wide a forum for addressing issues, which they saw as an infringement of their rights. This included human rights violations, but also violations of economic rights, as in the case of land claims and fishing rights (Lawlor 2006). It remains to be seen, whether UN DRIP will also have a bearing on attempts by indigenous groups to resist instances of biopiracy. It also remains to be seen, what will be the role of the World Intellectual Property Organization (WIPO) (Kim 2005).

The International Convention on Biological Diversity (CBD) under the patronage of the UN Environmental Program (UNEP) aims to protect rights of indigenous people since the early $1990 \mathrm{~s}$ by creating opportunities for the sustainable use of bioresources and conservation of biodiversity at the same time (Merson 2000). This treaty, however, was not signed by several countries, including U.S.A.

Another important attempt to protect rights on indigenous knowledge was the Nagoya Protocol on Access to Genetic Resources and the Fair and Equitable Sharing of Benefits Arising from Their Utilization to the Convention on Biological Diversity (Convention on Biological Diversity 2015). The Nagoya Protocol also included rules to protect traditional medicinal knowledge and to compensate for such knowledge that is already being patented or being used in an inappropriate manner. Although set up in the year 2010, it still awaits ratification by 50 nations.

In addition to policy making on a global scale, political frameworks have been developed for the concrete everyday work, such as the International Cooperative Biodiversity Groups Program and the Cooperative Research and Development Agreement of the National Cancer Institute, U.S.A. and many others (Aponte et al. 2009; Soejarto et al. 2005; Cragg et al. 2012; Cox et al. 2008).

Despite numerous efforts to protect natural resources and intellectual property rights of indigenous people on their traditional knowledge, we are far away from satisfying solutions and practical implementations (Lawrence 2004). The African Union (AU) has drafted the African Model. The main objective of this model legislation is to ensure the conservation, evaluation and sustainable use of biological resources. The specific goal is to recognize, protect and support the legitimate rights of local communities (like those involved in agriculture). Also this model attempts to devise a strategy to control the unwarranted access to intellectual as well as biological resources. In addition, the African Model does not recognize patents over life forms and biological processes (Convention on Biological Diversity \$16) rather it demands consultation and prior informed consent (PIC) for any form of access to them. Active participation of women as an impetus to improve their so- cial condition and also encouragement to grass-root level scientific techniques is a major focus area of this model (Convention on Biological Diversity $\$ \S 26$ and 28).

The model of the AU recognizes farmers' rights and is also focused towards protecting the same in order to obtain an equitable share of benefit arising from the use of plant and ancient genetic resources. Furthermore, AU intends to regulate exchange and selling of farm-produced seeds or propagating material so as to avoid any illegitimate transaction. It also emphasizes on safeguarding plant breeders' rights that stem from the efforts and investments made to develop new varieties and improve the overall scenario of national food security.

This sui generis model for the protection of traditional knowledge is appropriate. As this knowledge is passed verbally down the generations with no identifiable inventors, the patent law becomes hard to satisfy. Thus, it is difficult to meet the criteria of novelty and inventive step, subsequently protection of the rights of the indigenous sources become debatable.

In fact, it seems convenient to hold politicians accountable for the dilemma in realizing practical measures required for the protection of intellectual property rights. The $\S 8 \mathrm{j}$ and $\S 15$ of the Convention of Biological Diversity (1992) acknowledged the sovereign right of states over their natural resources, including the authority to determine access to genetic resources. It becomes mandatory to take necessary measures to ensure that the results and benefits of research utilizing these genetic resources are shared fairly with the nation of origin. Substantial efforts towards providing rationale benefits have resulted in the formulation of the Nagoya protocol in 2010, which aims to create a framework under international law (Convention on Biological Diversity 2010).

We as scientists studying medicinal plants have many opportunities to practically work against biopiracy and protect the rights of people particularly from developing countries. From a scientist's point of view, there are two solutions to tackle the problem. One is to let indigenous communities participate in patenting and earning revenues of commercialization of products. This sounds simple, but no anecdotes of its implementation have been recorded so far. From an ethical point of view, this is an indispensable obligation for companies fostering practices of sustainability and reciprocity. The same applies, if scientists at academia are collaborating with companies to develop medicinal and aromatic plants from indigenous tribes for the market.

Rather than drug marketing, scientists at universities frequently are interested in investigating plants for scientific advancement, e.g. clarification of chemical constituents, pharmacological modes of action in human cells etc. Then, they should not be suspected to collaborate with companies to generate products for the market without letting indigenous communities participate. Their scientific work should not be erroneously labeled as "hidden biopiracy" and hampered by environmentalists (Tan et al. 2006). On the other side, scientists working in the field of basic ethnopharmacology without intent to commercialize medicinal and aromatic plants or to transfer their knowledge to companies should take preventive measures to protect their scientific results against misuse by others for biopiracy purposes (see below).

A basic principle of the patent law is the novelty of an invention. It is not required that the invention represents a revolutionary novel development. Rather, it should be an improvement over the already existing technology (Kanoan 1999). The patent policy of an exclusive monopoly right ensures that research costs can be recouped and innovative works rewarded. Thus, an inventor has the right to exclude others from importing, selling, offering for sale or using the product for up to 20 years. To ensure that the public has the full benefit of inventions which fall into the public domain, it becomes indispensable for the inventor to disclose how to make use of the invention (Kanoan 1999). 
Published data are not patentable anymore. Academic science in general has an inherent attitude to make knowledge available to the scientific community (and as a consequence also to broader audiences) by publishing research data in scientific journals. Thus, one way of preventing biopiracy can be to get constantly engrossed in gaining and propagating scientific knowledge without intending to earn huge commercial benefits from the same. Therefore, scientific gain of knowledge without intention of commercial use of the knowledge can be a preventive measure against biopiracy. This represents an effective measure against burglary and patenting indigenous knowledge without participation of the communities, where this knowledge comes from. The same is true for presenting scientific data at conferences. Even unpublished results once presented in oral form (as speeches or lectures) or as posters cannot be patented thereby depleting the risk of a probable biopiracy attack. This is an easy and effective way for all of us to act against biopiracy. Let us publish more on medicinal and aromatic plants!

\section{Perspectives}

We feel, however, that our responsibilities are even broader. If medicinal and aromatic plants derived from developing countries are investigated in laboratories of industrialized countries, it is extremely important that scientists from these countries are made a part of the venture. They should participate in the scientific advancement made in such plants. Many laboratories around the globe have brought this principle into action. However, much more effort has to be made to emphasize its urgent necessity. The scientific investigation of medicinal and aromatic plants should include both, undergraduate and post graduate students as well as postdocs and guest scientists from the countries, where the plants have been derived from. Obtaining B.Sc., M.Sc. or Ph.D. degrees from reputed Universities of developed countries most frequently represents decisive milestones in the professional academic careers of young students. The same is true for postdoctoral and more advanced scientists, if they manage to publish in reputed international journals as a result of their research sojourns in laboratories of such universities. This represents a wonderful opportunity not only for scientific exchange and joint collaborations on medicinal and aromatic plants, but also for an effective promotion of young investigators from developing countries, which is based on the traditional knowledge of their own cultural background. Other than that, science and culture will remain an intruder evoking boundary experiences rather than mutual collaboration for the sake of human well-being and health.

In this context, it is also mandatory from our point of view to involve scientists of the home Universities of exchange students and scientists. Bridging the gap between industrialized and developing countries by scientific collaborations between universities creates a win-win situation for all participants. It fosters and acknowledges sustainable and responsible use of bioresources along with the protection of traditional knowledge of indigenous communities and serves towards the scientific advancement of research on medicinal and aromatic plants.

It is quite apparent that we as scientists do not need to wait for global politics protecting local rights and whether or not the next memorandum shall be ratified by all countries. Rather, we should act by ourselves. As documented in several literature databases, the fruitful publication activities of the PhytCancer participants can be taken as a proof for the success of numerous ethnopharmacological joint collaborations and also for the feasibility of this concept. Furthermore, we understand the increasing number of advancements of professional careers of students and awarding of prizes as stimulating impulses to continue our work with the philosophy outlined above. It is our conviction that we all can substantially contribute to ban biopiracy and to develop responsible strategies of bioprospecting for the sake of coming generations in both developing and industrialized countries. Let us start right now!

\section{Conflict of interest}

The authors declare to have no conflict of interest.

\section{Acknowledgment}

This work has been funded by the Deutsche Forschungsgemeinschaft (Grant \#GRK2015/1).

\section{References}

Abramova, I., Greer, A., 2013. Ethnochemistry and human rights. Chem. Biodivers. 10, 1724-1728.

Aponte, J.C., Vaisberg, A.J., Rojas, R., Sauvain, M., Lewis, W.H., Lamas, G., Sarasara, C., Gilman, R.H., Hammond, G.B., 2009. A multipronged approach to the study of peruvian ethnomedicinal plants: a legacy of the ICBG-Peru Project. J. Nat. Prod. 72, 524-526.

British Parliament, 1999. Trade Related Intellectual Property Rights (TRIPs) and Farmers' Rights. http://www.publications.parliament.uk/pa/cm199900/cmselect/ cmenvaud/45/45ap08.htm (accessed 18.10.15).

Brody, B.A., 2010. Intellectual property, state sovereignty, and biotechnology. Kennedy Inst. Ethics J. 20, 51-73.

Chen, J., 2006. There's no such thing as biopiracy...and it's a good thing too 37. McGeorge Law Review 1. http://nationalaglawcenter.org/publication/chentheres-no-such-thing-as-biopiracy-and-its-a-good-thing-too-37-mcgeorge-1rev-1-32-2006/wppa_open/. (accessed 18.10.15).

Convention on Biological Diversity, 1992. https://www.cbd.int/convention/text/. (accessed 18.10.15).

Convention on Biological Diversity, 2010. About the Nagoya Protocol. https://www. cbd.int/abs/about/. (accessed 18.10.15).

Convention on Biological Diversity, 2015. About the Nagoya Protocol. https://www cbd.int/abs/about/default.shtml/. (accessed 16.07.15).

Cox, P.A., Johnson, H.E., Tavana, G., 2008. Giving Samoan healers credit for prostratin. Science 320, 1589

Cragg, G.M., Katz, F., Newman, D.J., Rosenthal, J., 2012. The impact of the United Nations Convention on Biological Diversity on natural products research. Nat. Prod. Rep. 29, 1407-1423.

European Patent Convention, 1973. https://www.epo.org/law-practice/legal-texts/ archive/epc-1973.html. (accessed 18.10.15)

European Patent Office, 1991. Technical Board of Appeal. "Onco-Mouse II". October 3, 1990 - Case No. T19/90 -. In: President and Fellows of Harvard College. IIC Int Rev. Ind. Prop. Copyr. Law 22, 74-84.

Gupta, S.C., Kismali, G., Aggarwal, B.B., 2013. Curcumin, a component of turmeric: from farm to pharmacy. Biofactors 39, 2-13.

Hamilton, C., 2006. Biodiversity, biopiracy and benefits: what allegations of biopiracy tell us about intellectual property. Dev. World Bioeth. 6, 158-173.

Ho, C.M., 2006. Biopiracy and beyond: a consideration of socio-cultural conflicts with global patent policies. Univ. Mich. J. Law Reform 39, 433-542.

Intellectual Property Office of the United Kingdom. 1977. The Patents Act 1977 (as amended). https://www.gov.uk/government/uploads/system/uploads/ attachment_data/file/354942/patentsact1977011014.pdf. (accessed 18.10.15).

Kadidal, S., 1993. Plants, poverty and pharmaceutical patents, 103. The Yale L. J. 223, 238.

Kanoan, G.M., 1999. The Copyright Protection of Computer Software Programs, Databases and Works in Digital Networks. University of Khartum, Sudan Ph.D. thesis.

Kim, H.-S., 2005. Do not put too much value on conventional medicines. J. Ethnopharmacol. 100, 37-39.

Krattiger, A., 2009. Biopiracy, bioprospecting and crop genetic resources: access, wealth creation and benefit sharing. http://www.iphandbook.org/handbook globallearning/videos/Biopiracy/. (accessed 18.10.15).

Lawlor, M., 2006. Public native America. Rutgers University Press.

Lawrence, S., Skordis, J., 2004. Practical strategies to combat biopiracy. Lancet 363. 166.

Mackey, T.K., Liang, B.A., 2012. Integrating biodiversity management and indigenous biopiracy protection to promote environmental justice and global health. Am. J. Public Health 102, 1091-1095.

MacQueen, H.L., 1994. Extending intellectual property: producers vs. users. North. Irel. Leg. Q. 45, 30-45.

Merson, J., 2000. Bio-Prospecting or biopiracy: intellectual property rights and biodiversity in a colonial and postcolonial context. Osiris 15, 282-296.

Noble, R.L., 1990. The discovery of the vinca alkaloids - chemotherapeutic agents against cancer. Biochem. Cell Biol. 68, 1344-1351.

Puri, M., Masum, H., Heys, J., Singer, P.A., 2010. Harnessing biodiversity: the Malagasy Institute of Applied Research (IMRA). BMC Int. Health Hum. Rights 10 (Suppl. 1), S9.

Ray, L.E., 2009. Podophyllum peltatum and observations on the Creek and Cherokee Indians: William Bartram's preservation of Native American pharmacology. Yale J Biol. Med. 82, 25-36. 
Robinson, D.F., 2010. Confronting biopiracy: challenges, cases and international debates. https://books.google.de/books/about/Confronting_Biopiracy.html?id= J7qvJQiFd_AC\&hl=de. (accessed 18.10.15).

Shiva, V., 1999. Biopiracy: The Plunder of Nature and Knowledge. South End Press.

Soejarto, D.D., Fong, H.H.S., Tan, G.T., Zhang, H.J., Ma, C.Y., Franzblau, S.G. Gyllenhaal, C., Riley, M.C., Kadushin, M.R., Pezzuto, J.M., Xuan, L.T., Hiep, N.T. Hung, N.V., Vu, B.M., Loc, P.K., Dac, L.X., Binh, L.T., Chien, N.Q., Hai, N.V. Bich, T.Q., Cuong, N.M., Southavong, B., Sydara, K., Bouamanivong, S., Ly, H.M., Thuy, T.V., Rose, W.C., Dietzman, G.R., 2005. Ethnobotany/ethnopharmacology and mass bioprospecting: issues on intellectual property and benefit-sharing. J. Ethnopharmacol. 100, 15-22.

Tan, G, Gyllenhaal, C, Soejarto, DD, 2006. Biodiversity as a source of anticancer drugs. Curr Drug Targets 7, 265-277.

Tedlock, B., 2006. Indigenous heritage and biopiracy in the age of intellectual property rights. Explore (NY) 2, 256-259.

Timmermans, K., 2003. Intellectual property rights and traditional medicine: policy dilemmas at the interface. Soc. Sci. Med. 57, 745-756.

UN General Assembly. Washington 12; UN: 2007. United Nations Declaration on the Rights of Indigenous Peoples. A/RES/61/295.

Union international pour la protection des obtentions végétales (UPOV). Convention internationale pour la protection des obtentions végétales. 1991. http://www. upov.int/upovlex/fr/conventions/1991/act1991.html. (accessed 18.10.15).
United Nations Environment Programme. Indigenous peoples and their communities. 2015. http://www.unep.org/civil-society/MajorGroups/Indigenous PeoplesandtheirCommunities/tabid/52201/Default.aspx. (accessed 18.10.15).

United States Supreme Court, 1948. Funk Bros. Seed Co. V. Kalo Inoculant Co., p. 130 333U. S. 127 https://supreme.justia.com/cases/federal/us/333/127/case.html (accessed 18.10.15).

United States Supreme Court, 1980. Diamond v. Chakrabarty, 447 U.S. 303. https: //supreme.justia.com/cases/federal/us/447/303/case.html. (accessed 18.10.15).

United States Patent and Trademark Office, 1991. Amgen, Inc. V. Chugai Pharm. Co. Ltd., 927 F. 2d 1200 (United States Court of Appeals, Federal Circuit). http:// openjurist.org/927/f2d/1200. (accessed 18.10.15).

United States Patent and Trademark Office, 1993. In re Bell 991 F. 2d 781 (United States Court of Appeals, Federal Circuit). https://law.resource.org/pub/us/case/ reporter/F2/991/991.F2d.781.92-1375.html. (accessed 18.10.15).

World Intellectual Property Organization. 2015. WIPO is the global forum for intellectual property services, policy, information and cooperation. http://www.wipo. int/portal/en/index.html. (accessed 18.10.15).

World Trade Organization. Background and the current situation. https://www. wto.org/english/tratop_e/trips_e/art27_3b_background_e.htm. 2015b. (accessed 18.10.15).

World Trade Organization. Overview: the TRIPS agreement. https://www.wto.org/ english/tratop_e/trips_e/intel2_e.htm. 2015a. 